\title{
Sintering and Related Phenomena
}

\author{
M. QIAN (1) ${ }^{1,2}$ \\ 1.-Centre for Additive Manufacturing, School of Engineering, RMIT University, Melbourne, \\ VIC 3000, Australia. 2.—e-mail: ma.qian@rmit.edu.au
}

Sintering has a history of about 26,000 years and is well established today as an important component or new material fabrication method. ${ }^{1}$ At its meeting held in March 2016, the TMS Powder Materials Committee decided to choose Sintering and Related Phenomena as its technical emphasis for JOM in 2017. Nine papers were selected out of 15 submissions for the April 2017 issue of JOM following a thorough review process. The key features of each contribution are summarized as follows.

In the first article titled "The Emergence of Quantitative Sintering Theory from 1945 to 1955," R.M. German briefly reviewed the evolution of the sintering theory and concluded that the key changes in sintering concepts occurred in the 1945-1955 timeframe. The conclusion is based on the following two milestone developments: "this time span starts with the first quantitative neck growth model from Frenkel and ends with the quantitative shrinkage model from Kingery and Berg that included several transport mechanisms."

The second article, "Effects of $\mathrm{H}_{2}$ Atmospheres on Sintering of Low Alloy Steels Containing OxygenSensitive Master Alloys" by R. Calderon et al., presents a detailed study of the formation of methane observed in steels containing oxidationsensitive elements (e.g., $\mathrm{Cr}$ or $\mathrm{Mn}$ ) during sintering in $\mathrm{H}_{2}$. It was found that, "as a consequence of the methane formation, steels containing oxygen-sensitive master alloy additions and sintered in plain $\mathrm{H}_{2}$ show pronounced homogeneous decarburization, resulting in a dramatic decrease in the ultimate tensile strength and a consequent increase in elongation." This article represents an interesting and important contribution to the sintering of steels containing oxygen-sensitive elements.

The third article by H.P. Tang et al. deals with the "Effect of Pre-annealing on Sintering of Stainless Steel Fiber Felt." Stainless steel fiber felt is a class of unique porous metal materials used in industry.

Ma Qian is the JOM advisor for the Powder Materials Committee of the TMS Materials Processing and Manufacturing Division, and guest editor for the topic Sintering and Related Phenomena in this issue.
Nevertheless, their sintering process is not well understood. The authors examined more than 500 sintered joints through quantitate analyses of the data extracted from synchrotron radiation scanning and three-dimensional (3D) reconstruction. The normal size distribution of the sintered joints identified has important implications for the sintering of stainless steel fibers. In addition, they showed that fiber felt samples sintered without pre-annealing contained more and larger sintered joints. Consequently, tensile strength more than doubled. These findings make this study an important contribution to the fabrication of stainless steel fiber felt products by sintering.

High-entropy alloys (HEAs) have received increasing attention as a class of new metallic materials. The fourth article by B. Liu et al. deals with "Ultra-high Strength TiC/Refractory-High-Entropy-Alloy Composite Prepared by Powder Metallurgy." The authors reported the development of a TiC-based ceramic composite with refractory HEA binders, prepared by spark plasma sintering (SPS) of powder mixtures of $\mathrm{WC}, \mathrm{Mo}_{2} \mathrm{C}, \mathrm{TaC}, \mathrm{NbC}, \mathrm{VC}$, and $\mathrm{Ti}$ at $1500^{\circ} \mathrm{C}$ and $30 \mathrm{MPa}$ in vacuum. The resulting microstructure of the TiC/HEA composite consisted of ultra-fine $\mathrm{TiC}$ grains $(0.85 \mu \mathrm{m})$ and HEA grains $(1.8 \mu \mathrm{m})$ and exhibited a compressive strength of $>3000 \mathrm{MPa}$, compared with 1790 $2210 \mathrm{MPa}$ for conventional TiC cermets.

In the fifth article, J. Shen et al. report on "Highly Thermal Stable Microstructure in Mg Fabricated Via Powder Rolling." Commercially pure Mg powder (average size: $180 \mu \mathrm{m}$ ) was rolled into flakes, which were crushed into small pieces of less than $5 \mathrm{~mm}$. Spark plasma sintering (SPS) was then used to consolidate them into ingot samples in vacuum. The microstructure of the commercially pure $\mathrm{Mg}$ produced was found to be unexpectedly stable at $500^{\circ} \mathrm{C}$; e.g., the micro-hardness of the sample remained almost unchanged after $3 \mathrm{~h}$ at $500^{\circ} \mathrm{C}$. This new development suggests that commercially pure $\mathrm{Mg}$ may be used as a structural material at elevated temperatures. 
The sixth article by Y.F. Yang et al. discusses "Enhanced Homogenization of Vanadium in Spark Plasma Sintering of Ti-10V-2Fe-3Al Alloy from Titanium and $\mathrm{V}-\mathrm{Fe}-\mathrm{Al}$ Master Alloy Powder Blends." The authors showed that SPS markedly accelerated the homogenization of vanadium in the alloy and therefore resulted in a uniform microstructure of $\mathrm{Ti}-10 \mathrm{~V}-2 \mathrm{Fe}-3 \mathrm{Al}$ with superior mechanical properties in the as-sintered state (tensile strength $>1250 \mathrm{MPa}$ and elongation $>10 \%$ ), compared with hot-pressed $\mathrm{Ti}-10 \mathrm{~V}-2 \mathrm{Fe}-3 \mathrm{Al}$ made from the same powder materials. The mechanism was attributed to the intensive Joule heating effect generated by the direct current passing through the electric conducting powder blends.

The seventh article by B. Chen et al. deals with the "Effect of Spark-Plasma-Sintering Conditions on Tensile Properties of Aluminum Matrix Composites Reinforced with Multi-Walled Carbon Nanotubes (MWCNTs)." By combining high-energy ball milling, SPS, and extrusion, the authors were able to fabricate strong and ductile CNTs/Al composites, e.g., with ultimate tensile strength of $>360 \mathrm{MPa}$ and tensile elongation of $>10 \%$. Selection of the appropriate processing conditions holds the key to the fabrication of strong and ductile CNTs/Al composites.

In the eighth article in this compilation, J. Soyama and co-workers investigated the "Sintering Behavior and Microstructure Formation of Titanium Aluminide Alloys Processed by Metal Injection Molding." Ti-45Al-5Nb-0.2B-0.2C (at.\%) alloy (TNB-V5) and its variants $\mathrm{Ti}-45 \mathrm{Al}-3 \mathrm{Nb}-1 \mathrm{Mo}-$ $0.2 \mathrm{~B}-0.2 \mathrm{C}$ at. $\%$ and $\mathrm{Ti}-45 \mathrm{Al}-3 \mathrm{Nb}-1 \mathrm{Mo}-1 \mathrm{Si}-0.2 \mathrm{~B}-$ $0.2 \mathrm{C}$ at.\% were sintered. The microstructural evo- lution was studied. The most suitable sintering temperature was determined to be slightly above the solidus leading to low porosity $(<0.2 \%)$ and reasonable tensile properties (e.g., ultimate tensile strength $=607 \mathrm{MPa}$ and strain at fracture $=0.5 \%$ ).

In the ninth and final article in this collection, J.M. Byun and co-authors investigated the "Fabrication of $\mathrm{Ta}_{2} \mathrm{O}_{5}$ Dispersion Strengthened Mo-Si-B Alloy by Powder Metallurgical Method." Mo-8.9Si7.7B core-shell powder particles were first fabricated with the core being intermetallic compounds and the shell being nano-sized Mo solid solution. Then nano-sized $\mathrm{Ta}_{2} \mathrm{O}_{5}$ particles were coated on the surface of Mo-8.9Si-7.7B core-shell powder particles using a wet blending process, which used $\mathrm{TaCl}_{5}$ powder as a precursor to precipitate nano-sized $\mathrm{Ta}_{2} \mathrm{O}_{5}$ particles on the surface of the core-shell powder particles. Finally, an ideal microstructure composed of uniformly distributed $\mathrm{Ta}_{2} \mathrm{O}_{5}$ particles in a continuous Mo solid solution matrix was obtained by sintering the coated powder at $1400^{\circ} \mathrm{C}$ for $3 \mathrm{~h}$ in $\mathrm{H}_{2}$. The dispersion of nano-sized $\mathrm{Ta}_{2} \mathrm{O}_{5}$ particles in Mo-8.9Si-7.7B alloy induced effective oxide dispersed strengthening (ODS).

In summary, this selection of articles is published under the topic "Sintering and Related Phenomena" in the April 2017 issue (vol. 69, no. 4) of JOM and can be accessed via the JOM page at http://link. springer.com/journal/11837/69/4/page/1.

\section{REFERENCE}

1. R.M. German, Powder Metall. 56, 117 (2013). 